\title{
Wechsel des Verlages
}

Die Verlagshäuser Paul Parey und Blackwell Wissenschaft sind übereingekommen, alle wissenschaftlichen Bücher und Zeitschriften, die bislang bei Paul Parey erschienen sind, Blackwell Wissenschaft zu übertragen. Dieser Vertrag trat im Januar 1994 in Kraft. Der neue Verleger und der Schriftleiter bedanken sich ausdrücklich beim Verlag Paul Parey für die herausragende Arbeit, die in der Vergangenheit geleistet wurde, um die Zeitschrift FORSTWISSENSCHAFTLICHES CENTRALBLATT zu dem zu machen, was sie heute ist - eine weit verbreitete Quelle wissenschaftlicher Information höchster Güte für alle in dem Bereich Forstwesen, Umweltforschung und Naturschutz involvierten Wissenschaftler.

Blackwell Wissenschaft, eine Schwestergesellschaft von Blackwell Scientific Publications, Oxford, ist stolz darauf, die Herausgabe der Zeitschrift FORSTWISSENSCHAFTLICHES CENTRALBLATT fortsetzen zu können. Blackwell Wissenschaft wird jede Anstrengung unternehmen, das publizistische Niveau - d. h. die Bedeutsamkeit für die Leserschaft - zu wahren und nach Möglichkeit auszubauen. Unterstützt werden diese Anstrengungen durch die Schwestergesellschaften der Blackwell-Gruppe mit Niederlassungen in Europa und Übersee, die eine lange Tradition in der Herausgabe wissenschaftlicher Zeitschriften haben. Hierdurch werden gegenwärtige und künftige Anforderungen an eine internationale Zeitschrift erfült. Die Herstellung des FORSTWISSENSCHAFTLICHES CENTRALBLATT wird in Zukunft durch unsere Schwesterfirma MZV Wien ausgeführt.

Ebenso wie in der Vergangenheit sehen der Schriftleiter und seine im Herausgebergremium mitwirkenden Kollegen es als ihre vordringlichste Aufgabe an, dieses wissenschaftliche Feld Forstwesen, Umweltforschung und Naturschutz kontinuierlich weiter zu entwickeln und die Position der Zeitschrift zu stärken. Dieses Editorial ist eine willkommene Gelegenheit, unsere Leser zu bitten, uns auch weiterhin zu unterstützen, um dieses Ziel zu erreichen.

Schriftleitung

Professor Dr. Ulrich Ammer, Freising
Blackwell

Wissenschafts-Verlag GmbH

Dr. Axel Bedürftig

Freising - Berlin, im Juni 1994 